\title{
Effects of Pharmacologically Induced Changes in NMDA-Receptor Activity on Long-Term Memory in Humans
}

\author{
Thomas H. Rammsayer ${ }^{1}$ \\ Georg Elias Mueller Institute for Psychology, University of Göttingen, D-37073 Göttingen, Germany
}

\begin{abstract}
In a double-blind crossover design, either $30 \mathrm{mg}$ of the noncompetitive NMDA-receptor antagonist memantine or a placebo was administered to 40 healthy male volunteers. Twenty line drawings of objects and 20 photographs of unfamiliar faces were presented on a computer screen. After a retention interval of $80 \mathrm{~min}$, the participants' task was to select the original objects and faces from a set of 80 items. Results were analyzed applying a signal-detection-theory approach. Recognition performance for objects was significantly impaired under memantine as compared to placebo, whereas performance on face recognition was not affected. Findings support the notion of differential effects of NMDA-receptor antagonists on memory functions in humans.
\end{abstract}

Glutamate is one of the main excitatory neurotransmitters in the mammalian brain. The wide distribution of glutamate within the central nervous system suggests that it mediates normal neural transmission (Collingridge and Singer 1990; Scatton 1993) by activating three major classes of subreceptors: NMDA (N-methyl-D-aspartate), AMPA ( $\alpha$-amino-3-hydroxy-5-methyl-4-isoxazolepropionic acid), and kainate (cf. Danysz and Archer 1994). Abnormal excitatory glutamatergic neurotransmission has been suggested as a pathological mechanism in various disorders such as schizophrenia (Tamminga 1998; Duncan et al. 1999), hypoxic-ischemic brain damage (Choi and Rothman 1990; Scatton 1993), and Alzheimer's dementia (Greenamyre et al. 1988; Foster 1990; Lees 1993). Cognitive symptoms associated with ischemia or Alzheimer's disease are considered a consequence of overactivation of NMDA receptors by endogenous glutamate, which causes neurodegeneration caused by excitotoxicity (Meldrum and Garthwaite 1990; Thomas 1995). Several clinical studies showed that NMDA-receptor antagonists improve cognitive disturbances by inhibiting pathological overactivation of NMDA receptors (Ditzler 1991; Pantev et al. 1993; Müller et al. 1995; Winblad and Poritis 1999).

Under physiological conditions, however, inhibition of NMDA receptors suppresses long-term potentiation (LTP) and thus impairs learning and memory (Izquierdo 1994). Although a large number of animal studies support the notion that NMDA antagonists negatively affect learning and memory processes (for reviews, see Danysz and Archer

${ }^{1}$ Corresponding author.

E-MAIL trammsa@uni-goettingen.de; FAX 49-551-393662.

Article and publication are at www.learnmem.org/cgi/doi/ 10.1101/lm.33701.
1994; Aigner 1995), investigations on memory functions in humans after NMDA-receptor blockade are exceedingly scant. The very few existing studies provide ambiguous results. As can be seen from Table 1, the effects of NMDA antagonists on immediate and delayed verbal and nonverbal memory performance in humans remain unclear, whereas spatial memory was consistently shown to be unaffected by NMDA-antagonistic pharmacological treatment. This pattern of results suggests differential effects of NMDA-receptor antagonists on memory functions in humans.

To date, no human data on the functional relationship between NMDA-receptor activity and other declarative memory functions, such as long-term memory for objects and faces, appear to exist. This is important to note because, most interestingly, recent animal studies suggest that performance on long-term object recognition is positively related to NMDA-receptor activity (Puma et al. 1998; Winnicka and Wisniewski 1999). Therefore, this study was designed to further elucidate the effects of pharmacologically induced NMDA-receptor activity on additional types of declarative memory in humans. For this purpose, the effects of the noncompetitive NMDA-receptor antagonist memantine (1-amino-3,5-dimethyladamantan-hydrochlorid) on longterm memory for objects and faces were investigated in 40 healthy male subjects.

\section{RESULTS}

Means $( \pm$ SEM) of all dependent variables for the memantine and the placebo condition are given in Table 2 . Because of the fact that $50 \%$ of the subjects received memantine first and the other $50 \%$ received the placebo first, in an initial analysis the potential effects of order were examined by comparing recognition performance of both these groups

LEARNING \& MEMORY 8:20-25 @ 2001 by Cold Spring Harbor Laboratory Press ISSN1072-0502/01 \$5.00

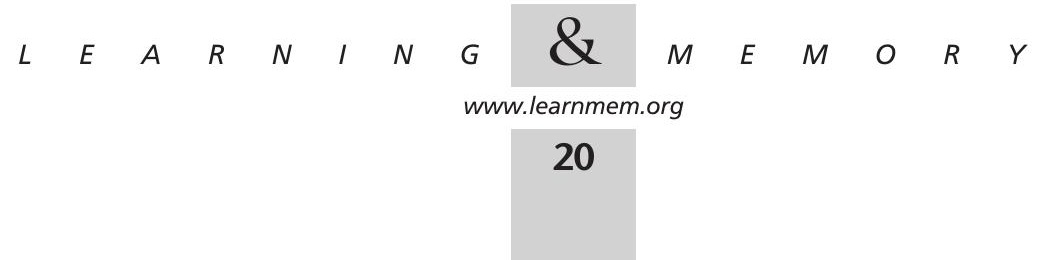


Table 1. Effects of Pharmacologically Induced Reduction of NMDA-Receptor Activity

\begin{tabular}{|c|c|c|c|c|}
\hline \multirow[b]{2}{*}{ Study } & \multicolumn{2}{|c|}{ Immediate recall } & \multicolumn{2}{|c|}{ Delayed recall } \\
\hline & Memory task & Outcome & Memory task & Outcome \\
\hline Krystal et al. 1994 & Verbal & 0 & Verbal & - \\
\hline Krystal et al. 1998 & Verbal & 0 & Verbal & - \\
\hline \multirow[t]{2}{*}{ LaPorte et al. 1996} & Verbal & 0 & Verbal & 0 \\
\hline & Nonverbal & 0 & & \\
\hline Newcomer et al. 1999 & Verbal & - & $\begin{array}{l}\text { Verbal } \\
\text { Nonverbal }\end{array}$ & $\overline{-}$ \\
\hline \multirow[t]{3}{*}{ Rockstroh et al. 1996} & Verbal & - & Verbal & 0 \\
\hline & Nonverbal & - & Nonverbal & - \\
\hline & Spatial & 0 & Spatial & 0 \\
\hline \multirow[t]{2}{*}{ Schugens et al. 1997} & Verbal & 0 & Verbal & 0 \\
\hline & Spatial & 0 & Spatial & 0 \\
\hline
\end{tabular}

(0) not significantly different from placebo; (-) statistically significant impairment compared to placebo. by pharmacologically induced changes in glutamatergic neurotransmission (see Fig. 1).

Although there was neither a significant main effect of Drug $(F(1,39)=$ 0.70 , nonsignificant) nor a significant interaction between Drug and Memory $(\mathrm{F}(1,39)=0.64$, nonsignificant $)$ with regard to response bias (c), a statistically significant main effect of Memory $(F(1,39)=4.37, P<0.05]$ could be established. The tendency to respond "new" was much more pronounced for the object than for the face recognition task, as indicated by $c$ values of 0.44 and 0.26 , respectively, but was unaffected by pharmacological treatment.

\section{DISCUSSION}

The major finding of this study was under placebo. There were no effects of order for both recognition tasks; mean performance on face recognition as indicated by the sensitivity measure $d^{\prime}$ was $1.68( \pm 0.24)$ and $1.85( \pm 0.24 ;[t(38)=0.62$, nonsignificant $]$, and mean performance on object recognition was $4.09( \pm 0.28)$ and 4.08 $( \pm 0.24 ;[t(38)=0.99$, nonsignificant $]$ for subjects who received placebo first and second, respectively. Furthermore, because the same set of stimuli was used in each experimental session, two-way analyses of variance with drugs (placebo and memantine) as two levels of a repeated-measurement factor and order of drug administration (placebo first and memantine first) as a grouping variable were computed to test for a significant interaction between drug status and order of drug administration on recognition memory. Neither for performance on face recognition $(F(1,38)=0.91$, nonsignificant $)$ nor for performance on object recognition $(F(1,38)=0.06$, nonsignificant $)$ could a statistically significant interaction be shown. This finding suggests that the factorial combinations of order of pharmacological treatment and drug status applied in this study did not exert any systematic effect on recognition memory, although the same set of stimuli was presented in each experimental session.

Two-way analysis of variance for repeated measurements with Drug and Memory (objects and faces) as two grouping factors revealed that recognition performance $\left(d^{\prime}\right)$ was markedly impaired by memantine $(F(1,39)=5.35$, $P<0.05)$. There also was a significant main effect of Memory $(F(1,39)=119.97, P<0.001)$, indicating a much higher sensitivity for objects than for faces. Furthermore, a statistically significant interaction between Drug and Memory could also be shown $(F(1,39)=6.97, P<0.05)$. Recognition performance for objects was significantly impaired under memantine as compared to placebo $(P<001)$, whereas performance on face recognition was not affected that NMDA-antagonistic pharmacological treatment produced a substantial performance decrement in delayed object recognition. This result indicates that the functional relationship between NMDA-receptor activity and performance on long-term object recognition, as observed in animal studies (Puma et al. 1998; Winnicka and Wisniewski 1999), also holds for human subjects. Unlike delayed recognition of objects, long-term memory for faces was not affected by memantine. In addition, recognition performance, as indicated by the sensitivity measure $d^{\prime}$, was reliably more than twice as high for object than for face recognition regardless of the pharmacological treatment applied. This finding is consistent with previous studies (Sergent et al. 1992; Farah et al. 1998; Rammsayer et al. 2000) also reporting better recognition performance with objects than with faces. As a possible explanation to account for this finding, Farah et al. (1998) put forward the

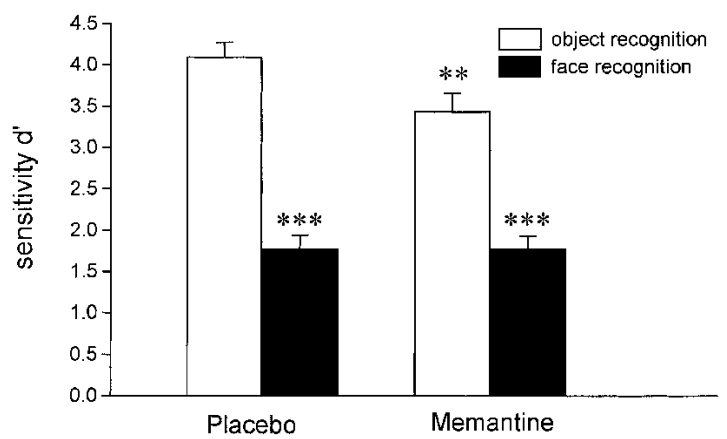

Figure 1 Performance on object and face recognition as indicated by the sensitivity measure $d^{\prime}$ under placebo and memantine. Note that better recognition performance is indicated by higher $d^{\prime}$ values. $\left.{ }^{* *}\right)$ significantly different from performance on object recognition under placebo $(P<0.01)$. $\left.{ }^{* * *}\right)$ significantly different from respective performance on object recognition $(P<0.001)$.

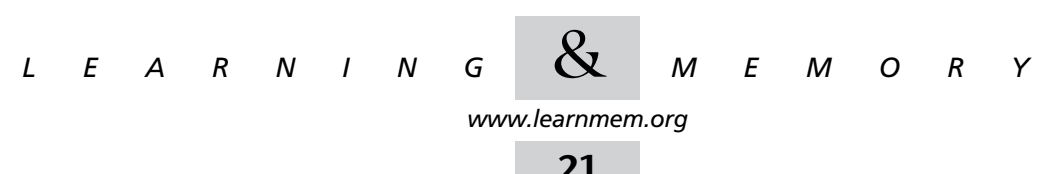


Table 2. Means and Standard Errors of the Mean of Indicators of Performance on Object and Face Recognition

\begin{tabular}{lrrrrr}
\hline & \multicolumn{2}{c}{ Placebo } & & \multicolumn{2}{c}{ Memantine } \\
& Mean & SEM & & Mean & SEM \\
\hline Object recognition: & & & & \\
$\quad$ hits (\%) & 89.75 & 1.56 & & 84.88 & 1.97 \\
$\quad$ false alarm (\%) & 3.12 & 0.85 & & 5.62 & 1.23 \\
$d^{\prime}$ & 4.09 & 0.18 & & 3.43 & 0.23 \\
$\quad c$ & 0.44 & 0.09 & & 0.44 & 0.07 \\
Face recognition: & & & & \\
$\quad$ hits (\%) & 70.25 & 3.35 & & 68.00 & 3.04 \\
false alarm (\%) & 20.25 & 2.54 & & 17.50 & 2.31 \\
$d^{\prime}$ & 1.77 & 0.17 & & 1.78 & 0.15 \\
c & 0.20 & 0.10 & & 0.32 & 0.09 \\
\hline
\end{tabular}

notion that faces are recognized more holistically, that is, using less part decomposition than other types of objects.

It should be noted, however, that there were some differences between both memory tasks that could be responsible for the differential effects of memantine. First, the objects were line drawings and thus may be easier to discriminate between and recognize than pictures of faces. This could imply that the differential effects of memantine were caused by perceptual differences rather than different brain areas involved in long-term memory for objects and faces. There is some evidence, however, that perceptual differences are unlikely to account for the results of this study. In several studies, NMDA-receptor antagonists were shown to produce only small effects (Krystal et al. 1994, 1998; Schulz et al. 1996) or no changes at all (LaPorte et al. 1996; Rockstroh et al. 1996; Newcomer et al. 1999) on various attentional, perceptual, or vigilance tasks. Similarly, in this study, there were no effects of memantine on a series of perceptual and psychomotor tasks (temporal discrimination, reaction time, critical flicker fusion frequency, and signal detection) completed by the subjects during the retention interval. Taken together, the available data do not support the notion that attentional factors or perceptual differences between processing of faces and objects were responsible for the differential effects of memantine.

Second, one may argue that the objects were all recognizable, nameable objects, whereas the faces were unfamiliar, unnameable faces. Furthermore, during the initial presentation phase subjects were instructed to name each object but only tell whether it was a male or female face (see Materials and Methods). Thus, the object recognition task could have become more of a verbal word-learning task, whereas verbal encoding was not possible for the faces. From this perspective, the significant memantine-induced performance decrement in delayed object recognition corresponds to the reports of substantial decreases in delayed verbal memory produced by NMDA-receptor antagonists (Krystal et al. 1994, 1998; Newcomer et al. 1999).
However, the lack of an effect of memantine on delayed face recognition observed in this study, in combination with the consistent finding that spatial memory is not affected by NMDA-receptor antagonists (Rockstroh et al. 1996; Schugens et al. 1997; Newcomer et al. 1999), points to the conclusion that some declarative memory functions, such as spatial memory and memory for faces, may be less susceptible to pharmacologically induced changes in NMDAreceptor activity than long-term verbal memory or object recognition.

Finally, the outcome of this study provides pharmacological evidence for the notion of different brain mechanisms underlying object and face recognition in humans. The brain mechanisms involved in facial processing were shown to be less susceptible to pharmacologically induced changes in NMDA-receptor activity than the ones associated with cognitive processing of objects. Whereas performance on face recognition was virtually unaffected by NMDA-receptor antagonistic treatment, performance on object recognition was markedly impaired.

Although recognition of objects and faces represents genuine declarative-memory functions (Zola-Morgan and Squire 1990; Squire et al. 1993), several lines of research suggest different brain systems underlying object and face recognition. Within the conceptual framework of declarative memory, the notion that face recognition involves different brain systems than do other types of object recognition is supported by neuropsychological studies demonstrating that face recognition can be selectively impaired (Levine 1989; Sergent and Signoret 1992; McNeil and Warrington 1993; Farah 1996; Henke et al. 1998). Similarly, EEG and PET studies also indicate a substantial degree of anatomic and functional specificity in face recognition (Seeck and Grüsser 1992; Sergent et al. 1992; Haxby et al. 1993; Allison et al. 1999), and electrophysiological studies in primates revealed neuronal assemblies that respond selectively to faces (Desimone 1991; Mesulam 1998; O'Scalaidhe et al. 1999). Neurophysiological studies in humans suggest that discrete regions of inferior extrastriate, midtemporal, and temporopolar cortex are specifically involved in facial recognition (Allison et al. 1999; Andreasen et al. 1996; Mesulam 1998). However, object recognition appears to depend on the perirhinal and postrhinal cortices (Meunier et al. 1993; Ennaceur et al. 1996; Ennaceur and Aggleton 1997; Buckley and Gaffan 1998a,b; Murray and Mishkin 1998; Parker and Gaffan 1998; Bussey et al. 1999). Thus, the observed detrimental effect of NMDA-antagonistic pharmacological treatment on long-term object recognition may be located in those brain systems specifically involved in object recognition.

An alternative explanation, however, is based on recent neuropsychological studies in nonhuman primates (Buckley and Gaffan 1997, 1998a,c; Murray et al. 2000). These studies suggest that perceptual difficulty of an iden-

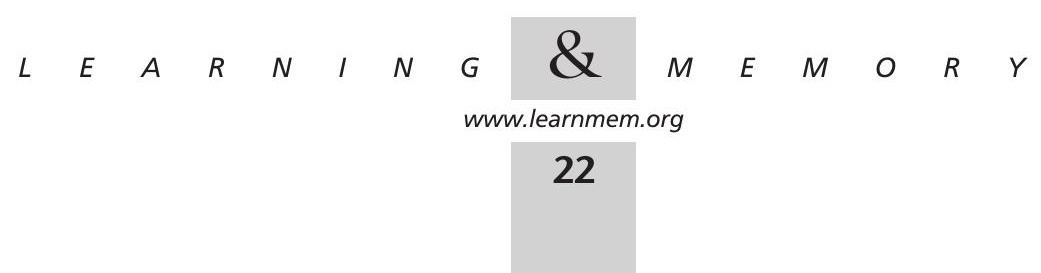


tification task can change the reliance of the task on perirhinal cortex. Therefore, one may assume that in this experiment the differential pharmacological effects of memantine could be caused by different ways of encoding visual stimuli of differing perceptual difficulty rather than different brain areas recognizing faces and objects. This interpretation may fit the observation that in all cases face recognition was poorer than object recognition. Although highly speculative at this point, one may also consider the hypothesis that such perceptual difficulty may effectively modulate the extent to which a given task is dependent on NMDAreceptor activity.

Because NMDA receptors exist throughout the entire cortical mantle, it remains an open question why different regions encoding objects and faces appeared to respond in different ways to NMDA-receptor antagonistic treatment. Differences in compensatory mechanisms, such as transneuronal feedback, may represent a possible explanation for the differential susceptibility of different brain regions (cf. Rammsayer 1989). A low level of transneuronal feedback may cause those functions mediated by a specific region to be particularly susceptible to any pharmacologically induced changes in neuronal activity. For example, dopaminergic mechanisms may modulate glutamatergic activity in the cortex by means of interaction at the level of the basal forebrain (Pralong and Jones 1993; Freed 1994; Svensson et al. 1994). Therefore, further studies applying a single behavior-multiple brain systems strategy (Solomon 1986) appear to be highly desirable to discover how different neurotransmitter systems in the brain contribute to specific memory functions.

\section{MATERIALS AND METHODS}

In a double-blind crossover design, either $30 \mathrm{mg}$ of the noncompetitive NMDA-receptor antagonist memantine (1-amino-3,5-dimethyladamantan-hydrochlorid) or a placebo were applied in a single oral dose in balanced order to 40 healthy male volunteers ranging in age from 20 to $35 \mathrm{yr}$ (mean $=26.0 \mathrm{yr}$ ). The subjects were tested at 1 -wk intervals, $5 \mathrm{~h}$ after drug intake. The study was approved by the research committee of the German Psychological Association.

Object stimuli were 40 unambiguous two-dimensional blackand-white line drawings of simple common objects. Face stimuli were black-and-white photographs of 40 unfamiliar faces of 20 males and 20 females ranging from 20 to $65 \mathrm{yr}$ of age. All faces were portrayed in three-quarter view and presented at a size of $\sim 12 \times 8.5$ $\mathrm{cm}$. All stimuli were presented at a size of $\sim 12 \times 8.5 \mathrm{~cm}$ on a computer monitor. Half of the objects and half of the faces were randomly selected and displayed as target stimuli, and the remainder were used as distractors. Objects and faces were randomly presented, one at a time, on the monitor screen for $4 \mathrm{sec}$ each, with an interstimulus interval (ISI) of $1 \mathrm{sec}$.

Subjects were instructed that each target object would be shown only once for a few seconds and that they should try to remember as many of the items as possible for a later recognition test. Furthermore, to control for attentional and/or perceptual difficulties, subjects were required to name each object and, in the case of faces, to tell whether it is a male or female face that is presented on the screen.

After a retention interval of 80 min during which the subjects completed several tasks (temporal discrimination, reaction time, $\mathrm{CFF}$, and a signal-detection task) not related to the object and face recognition, instructions for the recognition phase were given. The subjects' task was to select the original 20 target objects and target faces from a set of 40 objects and 40 faces by indicating those items that had been previously shown by the verbal response "old" and those items that had not been previously shown (i.e., distractor items) by the verbal response "new." The target and distractor items were presented in a random sequence for a duration of $4 \mathrm{sec}$ each with an ISI of $1 \mathrm{sec}$. Subjects' verbal responses were recorded by the experimenter.

As an indicator of recognition performance, frequency of correct recognitions and frequency of false alarms, that is, responding "old" to a (new) distractor item, were computed separately for objects and faces. Subsequently, these data were analyzed applying a signal-detection-theory (SDT) approach (Swets 1964; Green and Birdsall 1978). The advantage of this approach is that SDT supplies a pure index of recognition performance ("sensitivity") that is independent of whatever criterion is adopted by the individual for making a particular decision ("response bias"). As a measure of recognition performance, the sensitivity measure $d^{\prime}$ and, as a measure of response bias, the criterion $c$ were computed according to the procedure described by Macmillan and Creelman (1991). With these measures, better recognition performance is indicated by increasing $d^{\prime}$ values, whereas a positive response bias represents a tendency to say "new."

\section{ACKNOWLEDGMENTS}

This work was supported in part by grants from the Deutsche Forschungsgemeinschaft.

The publication costs of this article were defrayed in part by payment of page charges. This article must therefore be hereby marked "advertisement" in accordance with 18 USC section 1734 solely to indicate this fact.

\section{REFERENCES}

Aigner, T.G. 1995. Pharmacology of memory: Cholinergic-glutamatergic interactions. Curr. Opin. Neurobiol. 5: 155-160.

Allison, T., Puce, A., Spencer, D.D., and McCarthy, G. 1999. Electrophysiological studies of human face perception. I. Potentials generated in occipitotemporal cortex by face and non-face stimuli. Cereb. Cortex 9: 415-430.

Andreasen, N.C., O'Leary, D.S., Arndt, S., Cizadlo, T., Hurtig, R., Rezai, K., Watkins, G.L., Boles Ponto, L., and Hichwa, R.D. 1996. Neural substrates of facial recognition. J. Neuropsychiat. 8: 139-146.

Buckley, M.J. and Gaffan, D. 1997. Impairment of visual object-discrimination learning after perirhinal cortex ablation. Behav. Neurosci. 111: 467-475.

- 1998a. Perirhinal cortex ablation impairs visual object identification. J. Neurosci. 18: 2268-2275.

- 1998b. Perirhinal cortex ablation impairs configural learning and paired-associate learning equally. Neuropsychologia 36: 535-546.

-1998c. Learning and transfer of object-reward associations and the role of the perirhinal cortex. Behav. Neurosci. 112: 15-23.

Bussey, T.J., Muir, J.L., and Aggleton, J.P. 1999. Functionally dissociating aspects of event memory: The effects of combined perirhinal and postrhinal cortex lesions on object and place memory in the rat. $J$. Neurosci. 19: 495-502.

Choi, D.W. and Rothman, S.M. 1990. The role of glutamate neurotoxicity

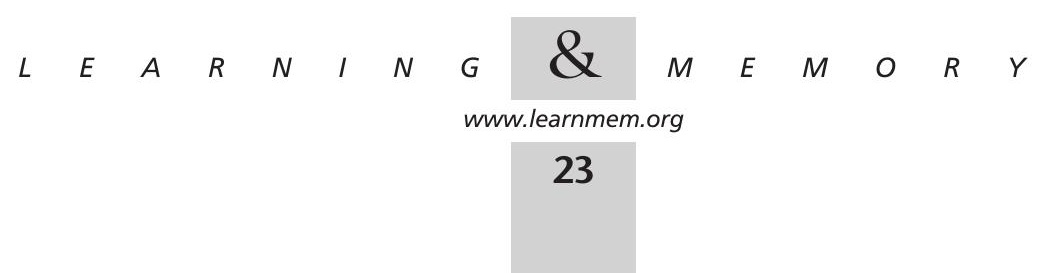


in hypoxic-ischemic neuronal death. Annu. Rev. Neurosci. 13: $171-182$.

Collingridge, G.L. and Singer, W. 1990. Excitatory amino acid receptors and synaptic plasticity. Trends Pharmacol. Sci. 11: 290-296.

Danysz, W. and Archer, T. 1994. Glutamate, learning and dementiaSelection of evidence. Amino Acids 7: 147-163.

Desimone, R. 1991. Face-selective cells in the temporal cortex of monkeys. J. Cognit. Neurosci. 3: 1-8.

Ditzler, K. 1991. Efficacy and tolerability of memantine in patients with dementia syndrome. Drug Res. 8: 773-780.

Duncan, G.E., Sheitman, B.B., and Lieberman, J.A. 1999. An integrated view of pathophysiological models of schizophrenia. Brain Res. Rev 29: 250-264

Ennaceur, A. and Aggleton, J.P. 1997. The effects of neurotoxic lesions of the perirhinal cortex combined to fornix transection on object recognition memory in the rat. Behav. Brain Res. 88: 181-193.

Ennaceur, A., Neave, N., and Aggleton, J.P. 1996. Neurotoxic lesions of the perirhinal cortex do not mimic the behavioural effects of fornix transection in the rat. Behav. Brain Res. 80: 9-25.

Farah, M.J. 1996. Is face recognition "special"? Evidence from neuropsychology. Behav. Brain Res. 76: 181-189.

Farah, M.J., Wilson, K.D., Drain, M., and Tanaka, J.N. 1998. What is "special" about face perception? Psychol. Rev. 105: 482-498.

Foster, A.C. 1990. Physiology and pathophysiology of excitatory amino acid neurotransmitter systems in relation to Alzheimer"s disease. Adv. Neurol. 51: 97-102.

Freed, W.J. 1994. Glutamatergic mechanisms mediating stimulant and antipsychotic drug effects. Neurosci. Biobehav. Rev. 18: 111-120.

Green, D.M. and Birdsall, T.G. 1978. Detection and recognition. Psychol. Rev. 85: 192-206.

Greenamyre, J.T., Maragos, E.F., Albin, R.L., Penney, J.B., and Young, A.B. 1988. Glutamate transmission and toxicity in Alzheimer's disease. Prog. Neuro-Psych. Biol. Psych. 12: 421-430.

Haxby, J.V., Grady, C.L., Horwitz, B., Salerno, J., Ungerleider, L.G., Mishkin, M., and Schapiro, M.B. 1993. Dissociation of object and spatial visual processing pathways in human extrastriate cortex. In Functional organisation of the human visual cortex (eds. B. Gulyas, D. Ottoson, and P.E. Roland), pp. 329-340. Pergamon Press, Oxford.

Henke, K., Schweinberger, S.R., Grigo, A., Klos, T., and Sommer, W. 1998 Specificity of face recognition: Recognition of exemplars of non-face objects in propagnosia. Cortex 34: 289-296

Izquierdo, I. 1994. Pharmacological evidence for the role of long-term potentiation in memory. FASEB J. 8: 1139-1145.

Krystal, J.H., Karper, L.P., Seibyl, J.P., Freeman, G.K., Delaney, R., Bremner, J.D., Heninger, G.R., Bowers Jr., M.B., and Charney, D.S. 1994. Subanesthetic effects of the noncompetitive NMDA antagonist, ketamine, in humans: Psychotomimetic, perceptual, cognitive, and neuroendocrine responses. Arch. Gen. Psych. 51: 199-214.

Krystal, J.H., Karper, L.P., Bennett, A., D'Souza, D.C., Abi-Dargham, A., Morrisey, K., Abi-Saab, D., Bremner, J.D., Bowers Jr., M.B., Suckow, R.F., et al. 1998. Interactive effects of subanesthetic ketamine and subhypnotic lorazepam in humans. Psychopharmacology 135: 213-229.

LaPorte, D.J., Lahti, A.C., Koffel, B., and Tamminga, C.A. 1996. Absence of ketamine effects on memory and other cognitive functions in schizophrenic patients. J. Psychiat. Res. 30: 321-330.

Lees, G.J. 1993. Contributory mechanisms in the causation of neurodegenerative disorders. Neuroscience 54: 287-322.

Levine, S.C. 1989. The question of faces: Special is in the brain of the beholder. In Handbook of research on face processing (eds. A.W Young and H.D. Ellis), pp. 37-48. Elsevier, Amsterdam.

Macmillan, N.A. and Creelman, C.D. 1991. Detection theory: A user's guide. Cambridge University Press, Cambridge.

McNeil, J.E. and Warrington, E.K. 1993. Prosopagnosia: A face specific disorder. J. Exp. Psychol. 46A: 1-10.

Meldrum, B. and Garthwaite, J. 1990. Excitatory amino acid neurotoxicity and neurodegenerative disease. Trends Pharmacol. Sci. 11: 379-387.
Mesulam, M.-M. 1998. From sensation to cognition. Brain 121: 1013-1052

Meunier, M., Bachevalier, J., Mishkin, M., and Murray, E.A. 1993. Effects on visual recognition of combined and separate ablations of the entorhinal and perirhinal cortex in rhesus monkeys. J. Neurosci. 13: 5418-5432.

Müller, W.E., Mutschler, E., and Riederer, P. 1995. Noncompetitive NMDA receptor antagonists with fast open-channel blocking kinetics and strong voltage-dependency as potential therapeutic agents for Alzheimer's dementia. Pharmacopsychiatry 28: 113-124.

Murray, E.A. and Mishkin, M. 1998. Object recognition and location memory in monkeys with excitotoxic lesions of the amygdala and hippocampus. J. Neurosci. 18: 6568-6582.

Murray, E.A., Bussey, T.J., Hampton, R.R., and Saksida, L.M. 2000. The parahippocampal region and object identification. Ann. N.Y. Acad. Sci. 911: $166-174$.

Newcomer, J.W., Farber, N.B., Jevtovic-Todorovic, V., Selke, G., Melson, A.K., Hershey, T., Craft, S., and Olney, J.W. 1999. Ketamine-induced NMDA receptor hypofunction as a model of memory impairment and psychosis. Neuropsychopharmacology 20: 106-118.

O'Scalaidhe, S.P., Wilson, F.A.W., and Goldman-Rakic, P.S. 1999. Face-selective neurons during passive viewing and working memory performance of rhesus monkeys: Evidence for intrinsic specialization of neuronal coding. Cereb. Cortex 9: 459-475.

Pantev, M.R., Ritter, R., and Görtelmeyer, R. 1993. Clinical and behaviora evaluation in long-term care patients with mild to moderate dementia under memantine treatment. Z. Gerontol. Psychiat. 6: 103-117.

Parker, A. and Gaffan, D. 1998. Interaction of frontal and perirhinal cortices in visual object recognition memory in monkeys. Eur. J. Neurosci. 10: 3044-3057.

Pralong, E. and Jones, R.S.G. 1993. Interactions of dopamine with glutamate- and GABA-mediated synaptic transmission in the rat entorhinal cortex in vitro. Eur. J. Neurosci. 5: 760-767.

Puma, C., Baudoin, C., and Bizot, J.C. 1998. Effects of intraseptal infusions of N-methyl-D-aspartate receptor ligands on memory in an object recognition task in rats. Neurosci. Lett. 244: 97-100.

Rammsayer, T. 1989. Is there a common dopaminergic basis of time perception and reaction time? Neuropsychobiology 21: 37-42.

Rammsayer, T. H., Rodewald, S., and Groh, D. 2000. Dopamine-antagonistic, anticholinergic, and GABAergic effects on declarative and procedural memory functions. Cognit. Brain Res. 9: 61-71.

Rockstroh, S., Emre, M., Tarral, A., and Pokorny, R. 1996. Effects of the novel NMDA-receptor antagonist SDZ EAA 494 on memory and attention in humans. Psychopharmacology 124: 261-266.

Scatton, B. 1993. The NMDA receptor complex. Fundam. Clin. Pharmacol. 7: 389-400.

Schugens, M.M., Egerter, R., Daum, I., Schepelmann, K., Klockgether, T., and Loschmann, P.A. 1997. The NMDA antagonist memantine impairs classical eyeblink conditioning in humans. Neurosci. Lett. 224: 57-60.

Schulz, H., Jobert, M., Coppola, R., Herrmann, W.M., and Pantev, M. 1996. The use of diurnal vigilance changes in the EEG to verify vigilance-enhancing effects of memantine in a clinical pharmacological study. Neuropsychobiology 33: 32-40.

Seeck, M. and Grüsser, O.-J. 1992. Category-related components in visual evoked potentials: Photographs of faces, persons, flowers and tools as stimuli. Exp. Brain Res. 92: 338-349.

Sergent, J. and Signoret, J.L. 1992. Varieties of functional deficits in prosopagnosia. Cereb. Cortex 2: 375-388.

Sergent, J., Ohta, S., and Macdonald, B. 1992. Functional neuroanatomy of face and object processing. Brain 115: 15-36.

Solomon, P.R. 1986. Strategies for studying brain-behavior relationships Behav. Brain Sci. 9: 344-345.

Squire, L.R., Knowlton, B., and Musen, G. 1993. The structure and organization of memory. Annu. Rev. Psychol. 44: 453-495.

Svensson, L., Zhang, J., Johannessen, K., and Engel, J.A. 1994. Effect of local infusion of glutamate analogues into the nucleus accumbens of

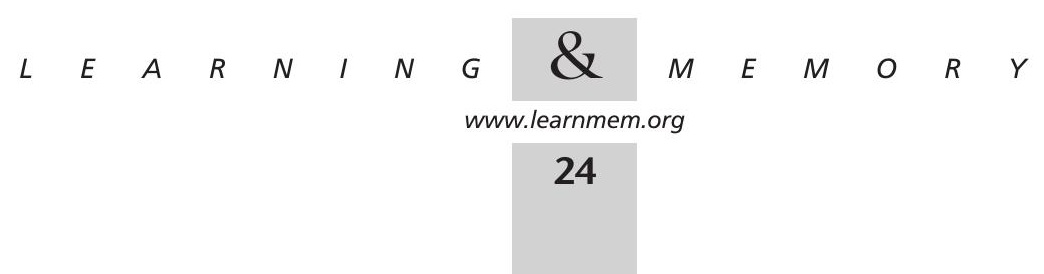


rats: An electrochemical and behavioural study. Brain Res. 643: 155-161.

Swets, J.A. 1964. Signal detection and recognition by buman observers. Wiley, New York.

Tamminga, C.A. 1998. Schizophrenia and glutamatergic transmission. Crit. Rev. Neurobiol. 12: 21-36.

Thomas, R.J. 1995. Excitatory amino acids in health and disease. J. Am. Geriatr. Soc. 43: 1279-1289.

Winblad, B. and Poritis, N. 1999. Memantine in severe dementia: Results of the sup-9M-Best study (benefit and efficacy in severely demented patients during treatment with memantine). J. Geriatr. Psych. 14: $135-146$
Winnicka, M.M. and Wisniewski, K. 1999. Disruption of temporo-entorhinal connections abolishes recognition memory-enhancing effect of angiotensins in rats. Gen. Pharmacol. 33: 91-97.

Zola-Morgan, S. and Squire, L.R. 1990. Neuropsychological investigations of memory and amnesia: Findings from humans and nonhuman primates. In The development and neural bases of higher cognitive functions (ed. A. Diamond), pp. 434-456. New York Academy of Sciences, New York.

Received May 16, 2000; accepted in revised form October 10, 2000.

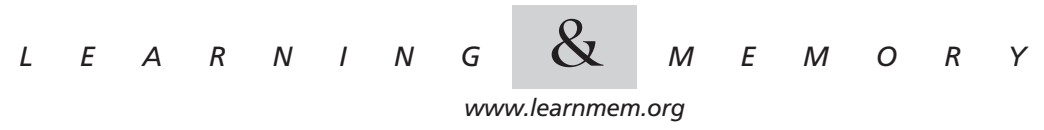




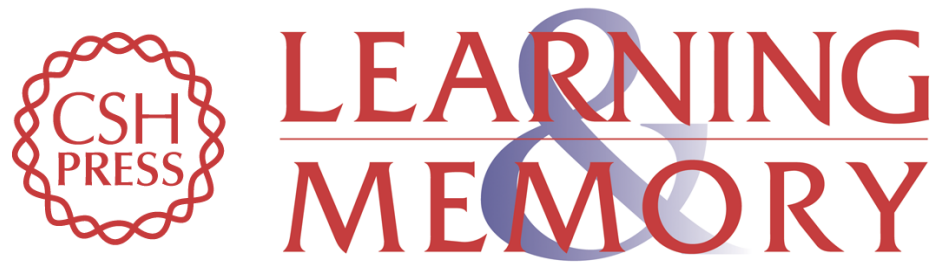

\section{Effects of Pharmacologically Induced Changes in NMDA-Receptor Activity on Long-Term Memory in Humans}

Thomas H. Rammsayer

Learn. Mem. 2001, 8:

Access the most recent version at doi:10.1101//m.33701

References This article cites 50 articles, 4 of which can be accessed free at: http://learnmem.cshlp.org/content/8/1/20.full.html\#ref-list-1

License

Email Alerting Receive free email alerts when new articles cite this article - sign up in the box at the Service top right corner of the article or click here. 